\title{
Evaluating Properties of Asphalt Mixtures Containing polymers of Styrene Butadiene Rubber (SBR) and recycled Polyethylene Terephthalate (rPET) against Failures Caused by Rutting, Moisture and Fatigue
}

Mahmoud Ameri, Reza Mohammadi, Milad Mousavinezhad, Amirhossein Ameri, Hamid Shaker Iran University of Science and Technology, Tehran, Iran.

Ameri@iust.ac.ir,R_mohammadi@civileng.iust.ac.ir,Miladmosavinezhad1992@gmail.com,Amir.ameri7293@yahoo.com, h_shaker@civileng.iust.ac.ir

Arash Fasihpour

Plan and Budget Organization, Tehran, Iran

Fasihpoun@yahoo.com

ABSTRACT. Properties of asphalt mixture play a vital role in structural integrity and performance of flexible pavements structure. In flexible pavements, asphalt concrete surface layer consists of asphalt binder, aggregates and in some cases additives.

In this research study styrene butadiene rubber (SBR) and recycled polyethylene terephthalate (rPET) are used to evaluate their individual and also their combinational effects on moisture susceptibly, rutting and low temperature cracking of asphalt concrete mixture.

Combinations of SBR, rPET and water were vulcanized to form thermoplastic elastomer polymers as bitumen modifier. Then conventional bitumen tests including penetration grade, softening point and rotational viscosity (RV) as well as asphalt mixture tests including resilient modulus, dynamic creep, IDT fatigue and moisture susceptibility tests were performed on binders and asphalt mixture specimens. The test results indicated that SBR and rPET increase viscosity and softening point and stiffen the binders by reducing their penetration grade. Test results of specimens prepared with modified binders showed higher tensile strength and higher rutting resistance than that of control specimen. Within the content of this study it is concluded that modification of bitumen with SBR reduces low temperature stiffness of binder and hence reduces failure due to thermal cracking and modification with rPET increases rutting resistance of the mixture at high temperatures.

KEYwORDS. SBR; rPET; Resilient modulus; Dynamic creep; Moisture susceptibility; Fatigue test.

\section{OPEN ACCESS}

Citation: Ameri, M., Mohammadi, R., Mousavinezhad, M., Ameri, A., Shaker, H., Fasihpour, A., Evaluating Properties of Asphalt Mixtures Containing polymers of Styrene Butadiene Rubber (SBR) and recycled Polyethylene Terephthalate (rPET) against Failures Caused by Rutting, Moisture and Fatigue, Frattura ed Integrità Strutturale, 53 (2020) 177-186.

Received: 12.03 .2020

Accepted: 04.05 .2020

Published: 01.07.2020

Copyright: (C) 2020 This is an open access article under the terms of the CC-BY 4.0, which permits unrestricted use, distribution, and reproduction in any medium, provided the original author and source are credited. 


\section{INTRODUCTION}

A

sphalt concrete is commonly used on the surface layer of flexible pavements of the roads and airports. This layer is directly affected by the environment and traffic loads and tolerates the highest level of pressur and stress. Thus, researchers have long been trying to improve the quality of the surface layer of flexible pavements by modifying aggregate, bitumen, and their optimum combination usage. It is a well-known fact that the viscoelastic behavior of asphalt concrete mixture results from its bitumen components. Therefore, asphalt pavement distresses such as permanent deformation and thermal cracking are related to the quality of asphalt binder utilized in asphalt mixtures [1].

There are various methods for improving the performance of asphalt mixture. Use of bitumen modifier is one of the common methods. The thermo-rheological behavior of bitumen causes it to act like a fragile solid at low temperatures, while at high temperatures, it flows and behaves like a Newtonian fluid. These characteristics increase the risk of cracking at low temperatures and rutting at high temperatures, and as a result, decrease the service life and increase the maintenance cost of asphalt pavements [2,3]. One of the most common categories of the bitumen modifiers is polymer materials. Among these polymers, elastomers, and thermoplastics, due to their ability to enhance overall viscoelastic properties of bitumen, have a great impact on bitumen characteristics and their resistance to distresses [4].

Elastomer polymers are a particular class of polymeric materials characterized by their resilience quality that permits them to stretch in response to stresses and easily return to their original shape when the force or stress is removed. The bitumen modified by elastomer polymer is more elastic and has less temperature sensitivity and a longer fatigue life. Also, these polymers decrease bitumen permeability and increase their softening point, resulting in higher resistance to rutting [2]. Crumb rubber (CR) and styrene butadiene (SB) are the most commonly used elastomer polymers in the asphalt industry and the combination of these materials, known as styrene butadiene rubber (SBR), is one of the most effective bitumen modifiers $[5,6]$.

When temperature is raised, thermoplastic polymers gradually become softer until they eventually become liquid-like and when the temperature is dropped, they turn into the solid-state again. Furthermore, thermoplastic polymers absorb aromatic oils and light fractions of bitumen, causing a decrease in penetration grade and an increase in bitumen viscosity. Also, these polymers increase softening point, leading to better adhesion and improvement of binder performance, particularly in wet conditions [7, 8]. Polyethylene (PE), Polypropylene (PP), and Ethylene Vinyl Acetate (EVA) are three thermoplastic polymers with a high potential to change the properties of binders and asphalt mixtures $[9,10]$.

Research has shown that adding crumb rubber increases bitumen complex modulus $\left(G^{*}\right)$ and decreases permanent deformation in asphalt mixtures [11]. SBR is another well-known polymer that is made from styrene, butadiene, and rubber which can positively change the properties of bitumen. More specifically, styrene increases elasticity, and butadiene increases the stiffness of bitumen. Also, SBR improves flexibility and elasticity of binders and asphalt mixtures, leading to higher resistance to low-temperature cracking. Hence, SBR modified binder is more suitable for areas with cold climate. [12, 13]. Despite the positive effects mentioned before, SBR cannot provide all the ideal characteristics of a binder. When the thermoplastic polymers is used in bitumen, the most important goals are to improve functional properties such as permanent deformation at high temperatures without adversely affecting other properties of asphalt mixtures such as fatigue and low temperature cracking. Studies have shown that Polyethylene (PE) modified binder has a higher complex modulus compared to that of the control sample. When PE is used as a bitumen modifier, the viscosity in high temperatures will increase, leading to greater mixture resistance to vehicle loads, and better performance of asphalt concrete mixture in hot-climate regions [14].

In order to prepare an asphalt binder that can be utilized in both high and low temperatures, researchers have used elastomer and thermoplastic polymers simultaneously together. Evaluation of rheological properties showed that bitumen modified with crumb rubber and polyethylene is a less thermally sensitive binder compared to the base bitumen [15]. Using recycled crumb rubber and polyethylene as bitumen modifiers increased the rutting resistance of mixtures at high temperatures and reduced thermal cracking at low temperatures [16].

Using recycled materials for bitumen modification not only improves the performance of asphalt concrete pavement, but also has many environmental benefits. Hence, many recycling additives such as crumb rubber, waste plastics, and recycled glass fiber have been used in the asphalt industry to reduce land consumption and save the natural resources for the next generations $[17,18]$. Plastic bottles are among the wide variety of man-made scrap materials which are generally produced from Polyethylene Terephthalate (PET). The recycled version of PET, known as rPET, is a thermoplastic powder-sized polymer that can be used for bitumen modification. Researchers have shown that as a bitumen modifier, rPET, can increase the adhesion and viscosity of binder, and at the same time increase the fatigue life of asphalt mixture [19].

In this study, SBR and rPET polymers, categorized as elastomer and thermoplastic polymers, were respectively evaluated to modify properties of the base bitumen and the corresponding asphalt mixtures. 


\section{EXPERIMENTAL METHODS}

7 ypically, aggregate forms $90 \%$ to $96 \%$ of the total weight of the asphalt mixture; hence, the structural, chemical and physical properties of these stone materials have a significant effect on the strength of asphalt mixtures [20,21]. The crushed limestone aggregates used in this study were obtained from the Asbcharan quarry located in the northeastern part of Tehran province, Rudehen. The gradation and specifications of aggregates are shown in Tab. 1.

\begin{tabular}{|c|c|c|c|c|c|c|}
\hline $\begin{array}{c}\text { Sieve } \\
\text { Number }\end{array}$ & Sieve size (mm) & \multicolumn{2}{|c|}{$\begin{array}{l}\text { Weight percentage } \\
\text { passing through each }\end{array}$} & Aggregate Test & Aggregate & Test Method \\
\hline $1 "$ & 25 & $\begin{array}{c}4.0 \text { GPA } \\
\text { scale } \\
-\end{array}$ & $\begin{array}{c}\text { Average } \\
\text { value } \\
-\end{array}$ & $\begin{array}{c}\text { Bulk specific } \\
\text { gravity }\end{array}$ & 2.484 & ASTM C127 \\
\hline $3.4^{\prime \prime}$ & 19 & 100 & 100 & \multirow{4}{*}{$\begin{array}{l}\text { Absorption } \\
\text { course } \\
\text { aggregate }(\%)\end{array}$} & \multirow{4}{*}{2.1} & \multirow{2}{*}{ ASTM 127} \\
\hline $1.2^{\prime \prime}$ & 12.5 & $90-100$ & 95 & & & \\
\hline $3.8^{\prime \prime}$ & 9 & - & - & & & \multirow{5}{*}{ ASTM 128} \\
\hline$\# 4$ & 4.75 & $44-74$ & 59 & & & \\
\hline$\# 8$ & 2.36 & $28-58$ & 43 & \multirow{3}{*}{$\begin{array}{c}\text { Absorption } \\
\text { fine aggregate } \\
(\%)\end{array}$} & \multirow{3}{*}{4.3} & \\
\hline \#16 & 1.18 & - & - & & & \\
\hline \#30 & 0.5 & - & - & & & \\
\hline$\# 50$ & 0.3 & $5-21$ & 13 & \multirow{3}{*}{$\begin{array}{c}\text { Los Angeles } \\
\text { abrasion Loss } \\
(\%)\end{array}$} & \multirow{3}{*}{23} & \multirow{3}{*}{ AASHTO T96 } \\
\hline \#100 & 0.15 & - & - & & & \\
\hline \multirow[t]{2}{*}{ \#200 } & 0.75 & $2-10$ & 6 & & & \\
\hline & & & & $\begin{array}{l}\text { Tow Fracture } \\
\text { faces }(\%)\end{array}$ & 93 & ASTM D5821 \\
\hline \multicolumn{4}{|c|}{ a) Grading limit used in the research study } & b) Enginee & operties o & regate source \\
\hline
\end{tabular}

Asphalt binder is an essential component of asphalt concrete mixture, and it is the binder that holds aggregate together. The quality of the asphalt binder is directly related to the performance of the asphalt mixture [22]. In this experimental investigation, a 60-70-penetration-grade binder obtained from Tehran's Pasargad Oil Company was used. To characterize the properties of the asphalt binder, conventional tests including penetration, softening point and ductility test were carried out. Tab. 2 presents the basic properties of the base bitumen.

\begin{tabular}{cccc}
\hline Test & Method & criteria & Result \\
Penetration of 25 c 100gr, & ASTM D5 & $60-70$ & 68 \\
(0.1mm) & & & \\
Softening Point (C) & ASTM D36 & $45-54$ & 48 \\
Ductility of 25 (cm) & ASTM D113 & 100 & 100 \\
Flash point (C) & ASTM D92 & 250 & 300 \\
Fire Point (C) & ASTM D70 & 230 & 315 \\
Specific gravity at 25 C & ASTM D70 & $1.05-1.06$ & 1.048 \\
Kinematic viscosity 120C (cSt) & ASTM D2170 & - & 815 \\
Kinematic viscosity 135C (cSt) & ASTM D2170 & - & 425 \\
Kinematic viscosity 150C (cSt) & ASTM D2170 & - & 235 \\
Penetration index (PI) & - & $-2 \leq P I \leq 2$ & -1.15 \\
Penetration viscosity number & - & - & -0.55 \\
(PVN) & & & \\
\hline
\end{tabular}

Table 2: Basic properties of the 60-70 penetration-grade asphalt binder 
The properties of SBR polymer and rPET, which is produced from shredding recycling bottles are presented in Tab. 3 .

\begin{tabular}{cc}
\hline Property & Value \\
Diffractive index & 1.4 \\
Density & 1.05 \\
Viscosity & $50 \mathrm{gr} /(\mathrm{cm} . \mathrm{s})$ \\
$\left(@ 100^{\circ} \mathrm{C}\right)$ & \\
Tensile strength & $20 \mathrm{MPa}$ \\
$\left(@ 145^{\circ} \mathrm{C}, 35 \mathrm{~min}\right.$, & \\
$500 \mathrm{~mm} / \mathrm{min})$ & \\
Conductivity & $130.3 \mu \mathrm{s} / \mathrm{cm}$ \\
\hline
\end{tabular}

a) SBR properties

\begin{tabular}{cc}
\hline Property & Value \\
Average molecular weight & $30,000-80,000$ gr.mol-1 \\
Density & 1.4 gr.cm-3 \\
Melting temperature & $255-265^{\circ} \mathrm{C}$ \\
Glass transition & $70-115^{\circ} \mathrm{C}$ \\
Temperature & $1700 \mathrm{MPa}$ \\
Young's modulus & $0.5 \%$ \\
Water absorption $(24 \mathrm{~h})$ &
\end{tabular}

b) rPET properties

Table 3: Properties of SBR and rPET polymers in this study

\section{Sample preparation}

In order to find the optimum asphalt binder content, the asphalt mixtures were designed and fabricated by using the standard marshal mix design method in accordance with ASTM D1599. Aggregates were heated for $24 \mathrm{~h}$ at the temperature of $180^{\circ} \mathrm{C}$, then mixed with $140^{\circ} \mathrm{C}$ binder with different contents. Marshal specimens were fabricated by applying 75 blows on each side of cylindrical samples to simulate heavy-traffic loading [23]. Three similar specimens were used for each binder percentage, to increase the precision of optimum binder content determination. The optimum binder content was determined to be $5.6 \%$ based on maximum stability, maximum bulk specific gravity and designed limits including 4 percent air voids, percent voids in mineral aggregates and median of other limits for satisfactory asphalt mixture.

Based on previous research, the optimum mixing content of SBR and rPET are $5 \%$ and $10 \%$ of the weight content of the base bitumen, respectively $[24,25]$. In this research study, both additives were replaced as part of the bitumen with portions of $0 \%, 25 \%, 50 \%, 75 \%$, and $100 \%$ of their optimum weight values. The additives were blended with bitumen, using a high shear mixer at $175{ }^{\circ} \mathrm{C}$ for 30 minutes at speed of $5000 \mathrm{rpm}$ [26]. The different modified binders prepared for this research are presented in Tab. 4.

\begin{tabular}{cc}
\hline Sample & Composition \\
N1 & base bitumen \\
N2 & base bitumen with $5 \%$ SBR \\
N3 & base bitumen with $3.75 \%$ SBR and $2.5 \%$ rPET \\
N4 & base bitumen with $2.5 \%$ SBR and $5 \%$ rPET \\
N5 & base bitumen with $1.25 \%$ SBR and $7.5 \%$ rPET \\
N6 & base bitumen with $10 \%$ rPET \\
\hline
\end{tabular}

Table 4: different modified binder constituents used in this research study

\section{RESULT AND DISCUSSION}

\section{Penetration Grade Results}

$\mathrm{P}$ enetration test is a method to measure hardness and consistency of bituminous materials in accordance with ASTMD5 $[27,28]$. The test is conducted at $25^{\circ} \mathrm{C}$. The results of penetration test of base bitumen (control sample) and modified binders are presented in Fig. 1. Based on the test results presented in Fig. 1, it can be seen that modified binders (at all combination levels of SBR and rPET) are stiffer and have lower penetration indicia than the base bitumen. As can be observed from the test results presented in Fig. 1 show that with quantitative increase in the percent weight of $\mathrm{SBR}$ and $\mathrm{rPET}$ in the additive admixtures the binder penetration value is decreased. 


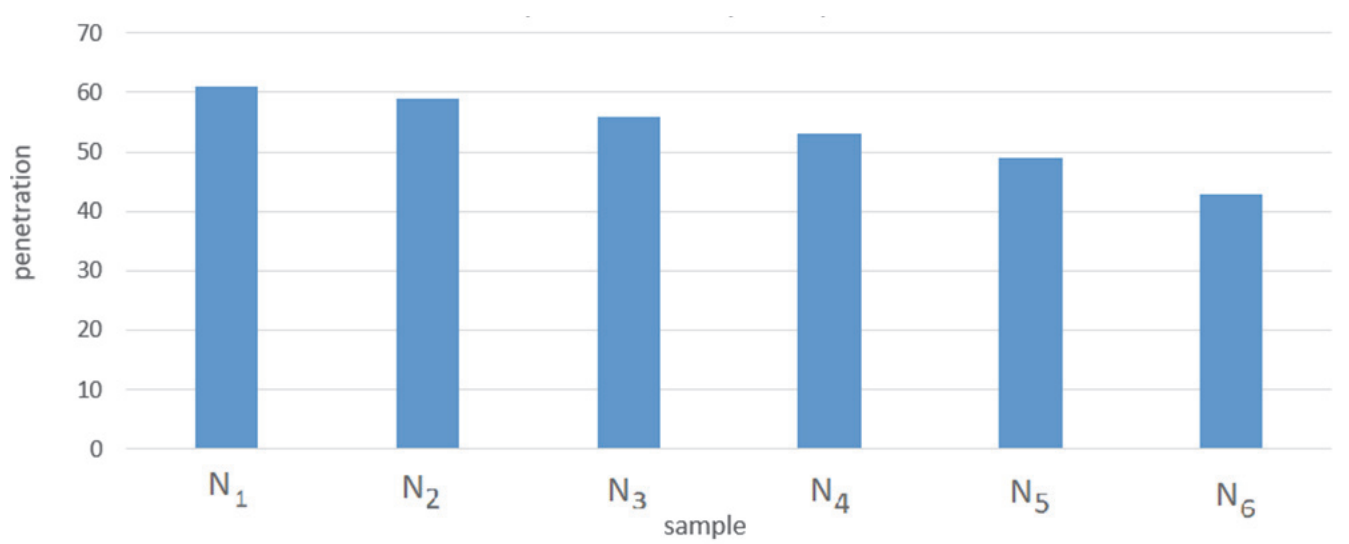

Figure 1: Penetration test results of the modified binders and the base bitumen

\section{Softening point test results}

The softening point is a temperature at which a substance attains a particular degree of softening.

It is a conventional test conducted on bituminous materials to measure their consistency at high temperatures in accordance with ASTM-D36 test method [29].

The results from softening point test of base bitumen and modified binders are presented in Fig. 2. As can be seen modification of the base bitumen with SBR and rPET additive admixtures at all combination levels will increase the softening points of the modified binders. The increase in softening point of the modified binder takes an upward trend when additives (SBR and rPET) quantity is increased in the admixture. It should be pointed out that when binder softening point increases, higher temperature is required to liquify the binder.

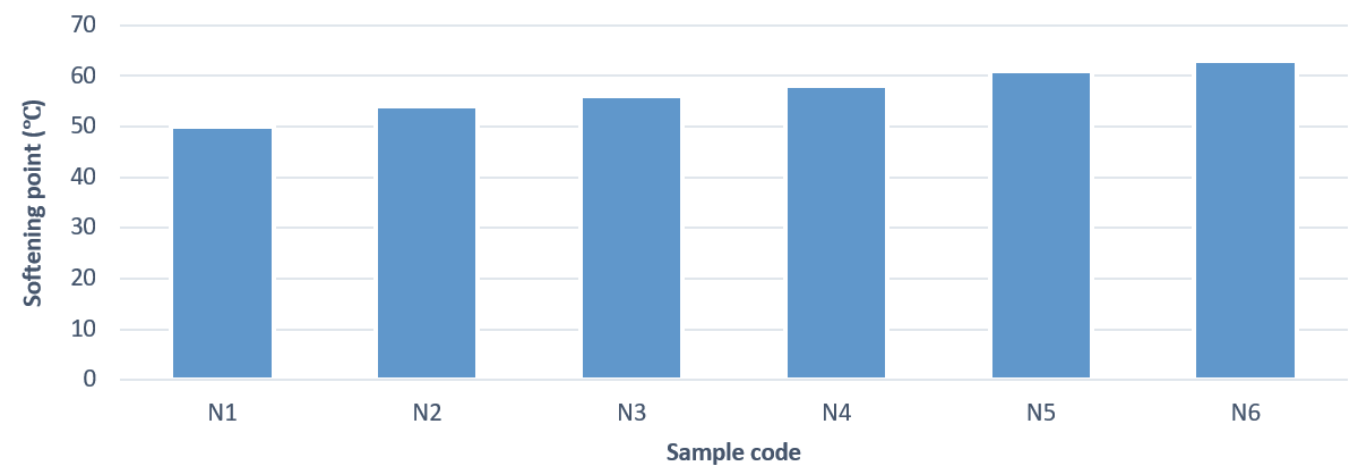

Figure 2: softening point test results of the modified samples and the base bitumen.

Rotational viscosity test $(\mathrm{R} V)$ results

Viscosity is an important rheological property for measuring the consistency of bitumen. It is defined as the ratio of the applied shear stress to the rate of shear strain [30]. The test is performed in accordance with ASTM-D44020 [31]. Bituminous binder typically exhibit newtonian behavior at high temperatures above $150^{\circ} \mathrm{C}$. However, they exhibit non-newtonian behavior as the temperatures decreases, then their viscosity becomes dependent on the shear strain rate. The temperature at which the non-newtonian behavior dominates depends on binder type. Nowadays the most practical means to measure the viscosity of bituminous materials is the rotational viscometer device that makes the measurement of viscosity of binders possible at various temperature. Fig. 3 shows the trend of viscosity changes of binders as function of type and contents of SBR and rPET modifiers at $135^{\circ} \mathrm{C}$. As can be observed from this figure the viscosities of modified binders at all combination levels of SBR and rPET are increased and are within the limits specified by Strategic Highway Research Program (SHRP) committee.

Gyratory asphalt concrete sample preparation

Gyratory samples were prepared in accordance with ASTM-D6924, with the optimum binder contents obtained from Marshall test method. To ensure proper viscosity of modified binders at mixing and compaction temperatures, the aggregates and modified binders were mixed and compacted by super pave gyratory compactor (SGC) at various 
temperatures corresponding to viscosities obtained from RV test results. The diameter and highest of cylindrical mold used to compact asphalt mixture samples were $100 \mathrm{~mm}$ and $62.5 \mathrm{~mm}$ respectively. The air void content for all samples was set to $4 \%$ [32]. In this investigation a total of 72 samples were fabricated based on a minimum of three replicate samples per mix, per test type.

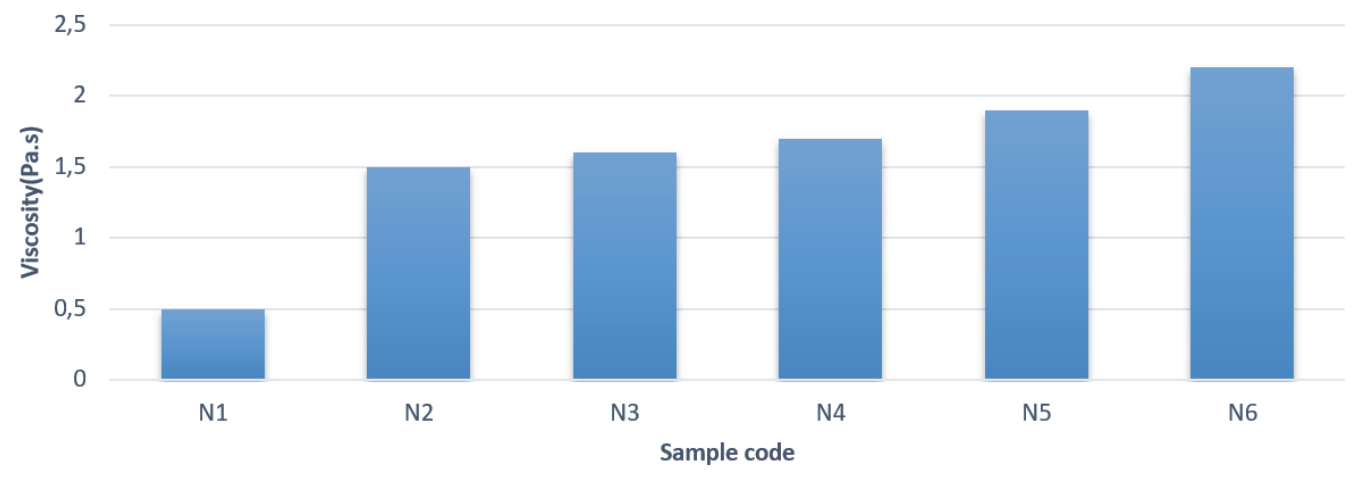

Figure 3: Rotational viscosity test results of the modified binders and the base bitumen

\section{Resilient modulus test results}

In the first step, the resilient modulus test was conducted on each specimen, considering the fact that the test is a nondestructive. Resilient modulus is defined as the ratio of the repeated axial deviator stress to the recoverable axial strain [33]. Resilient modulus is one of the main factors in designing asphalt concrete pavements. It shows the asphalt's potential for possible deformations based on the relation between stress and strain under a specific load [34]. In this research study, the resilient modulus value was determined in accordance with ASTM-D4123, by using the UTM5 device. The 450N load was applied with $0.1 \mathrm{~s}$ loading time and $0.4 \mathrm{~s}$ rest period, while the temperature was set at $25^{\circ} \mathrm{C}$. The resilient modulus is calculated by Eq. 1 [35].

$$
M_{r}=\mathrm{P}(\nu+0.2734) / \text { t. } \Delta b
$$

where $M_{r}$ is the resilient modulus (MPa), $\mathrm{P}$ is the repetitious load $(\mathrm{N}), \nu$ is the Poisson ratio (assumed to be 0.35 ), $\mathrm{t}$ is the sample's thickness $(\mathrm{mm})$, and $\Delta b$ is the horizontal reversible deformation $(\mathrm{mm})$.

According to Fig. 4, the value of the resilient modulus of all specimens prepared with modified binders increased about 100 percent compared to the control sample. To explain this change, it can be noted that asphalt mixes modified with SBR have more elasticity relative to control sample, and the application of rPET in asphalt mixes increase the adhesion between binder and aggregates. The fact that incremental difference between the resilient modulus values of specimens with different additive type and additive contents is not significant, indicates that SBR and rPET have similar influence on permanent deformation potentials of asphalt mixtures.

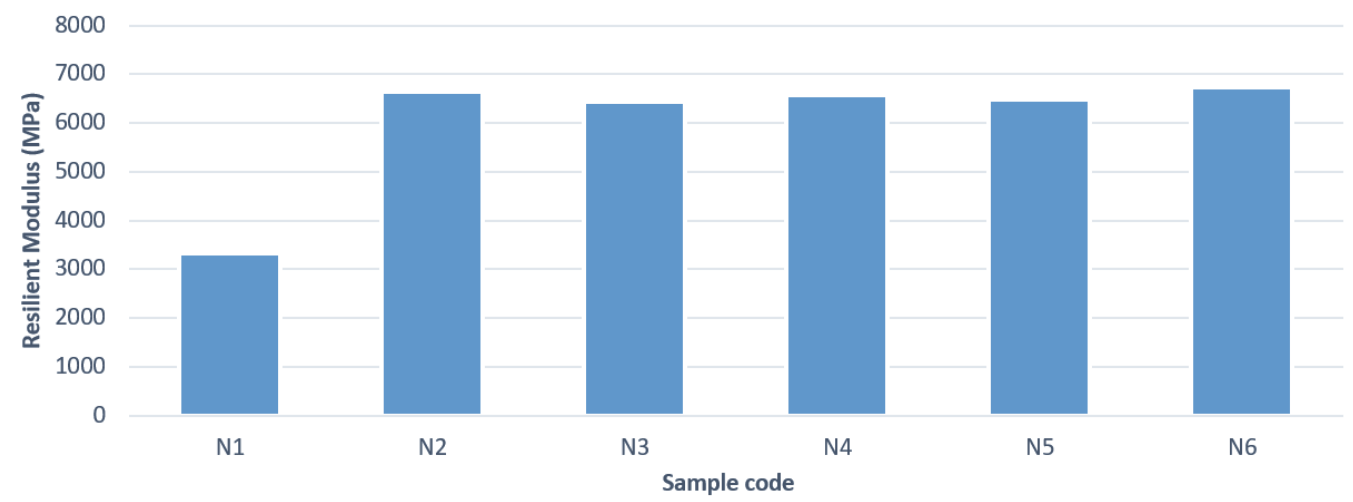

Figure 4: The resilient modulus values of the modified and the control mixture 
Dynamic creep test results

In this study flow number $(\mathrm{FN})$ is used to evaluate and compare the rutting resistance of all mixtures. FN is defined as the number of load cycles at which the rate of change of compliance of a mixture is minimum. Higher FN value indicates a more stable asphalt mixture with higher resistance to rutting [36, 37]. The FN values calculated from dynamic creep test results of samples per binder type are shown in Fig. 5.

As can be observed from the results presented in Fig. 5 the FN values and hence the rutting resistance of all mixes prepared with admixtures of SBS and rPET binder are higher than that of the control mixture. The highest rutting resistance belongs to the sample prepared with 10 percent rPET. This phenomenon may be attributed to increase in viscosity and adhesive effect of rPET.

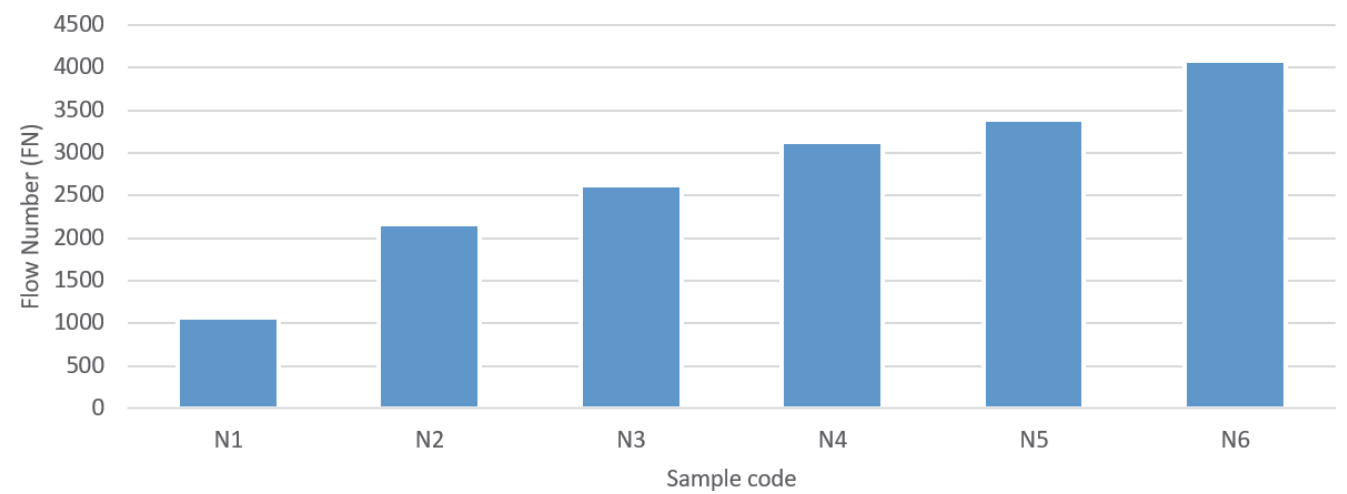

Figure 5: Number of cycles to failure (flow number) obtained from dynamic creep test

\section{Moisture susceptibility test results}

The moisture susceptibility of asphalt mixtures is assessed by measuring their tensile strength in wet and dry conditions in accordance with AASHTO-T283 standard [38]. The tensile strength ratio (TSR) is defined as the ratio of the ensile strength of the conditioned (or wet) specimens to that of the dry specimens [39]. The higher the TSR value, the higher the resistance of the mixture to moisture damage $[40,41]$. Fig. 6 shows the trend of TSR changes as a function of rPET content in the mixtures. As can be observed from this figure the TSR value is increased with increase in rPET content in the mixtures. Hence, it may be deduced that modification of bitumen with rPET polymeric materials will enhance resistance of asphalt mixtures against moisture damage. The increase in moisture resistance of the asphalt mixtures prepared with $\mathrm{rPET}$ modified binder might be due to conspicuous adhesive effect of rPET modified binder which enhances cohesive bonding between aggregates in the asphalt mixture skeleton.

The results also show that the TSR values of all mixture prepared with rPET and SBR modified binders satisfy the minimum requirement of $80 \%$ suggested by many asphalt agencies worldwide. A possible explanation for increase in moisture resistance of asphalt mixtures containing SBR may be attributed to the styrene content of the SBR which increases the elasticity of the modified binder leading to higher tensile strength value of the mixture [5].

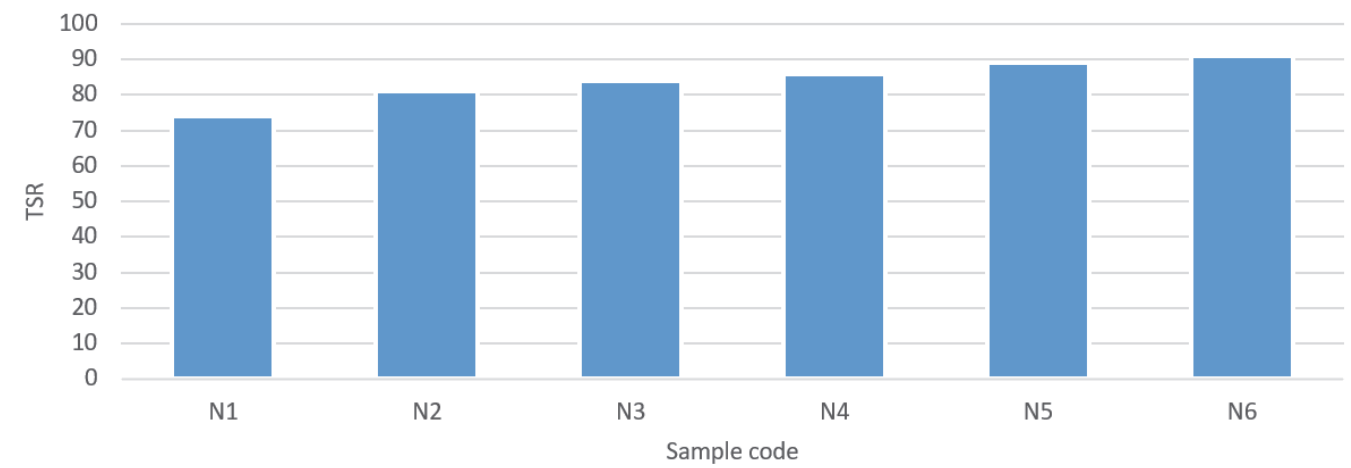

Figure 6: TSR (Tensile Strength Ratio) test results of the modified and the control. 


\section{Indirect tensile fatigue test results}

Fatigue cracking due to low temperature drop in pavement structures has been a major concern of pavement design engineers, because these types of cracking are generally developed within the pavement structure [42]. To understand the fatigue performance of asphalt mixture prepared with binders at varying combination levels of SBR and rPET modifiers, their behavior were evaluated by repeated load indirect tension test at $0^{\circ} \mathrm{C}[43]$ The test results are presented in Fig. 7 .

The results presented in this figure show that fatigue resistance of all mixtures prepared with modified binders is significantly increased and is higher than that of the control mixture. The results also show that, the fatigue parameter of mixture designated as N2 is almost ten times higher than that of the control mixture, indicating that SBR modified binder greatly reduces the low temperature susceptibility of the mixtures and also reduces the chance of thermal cracking.

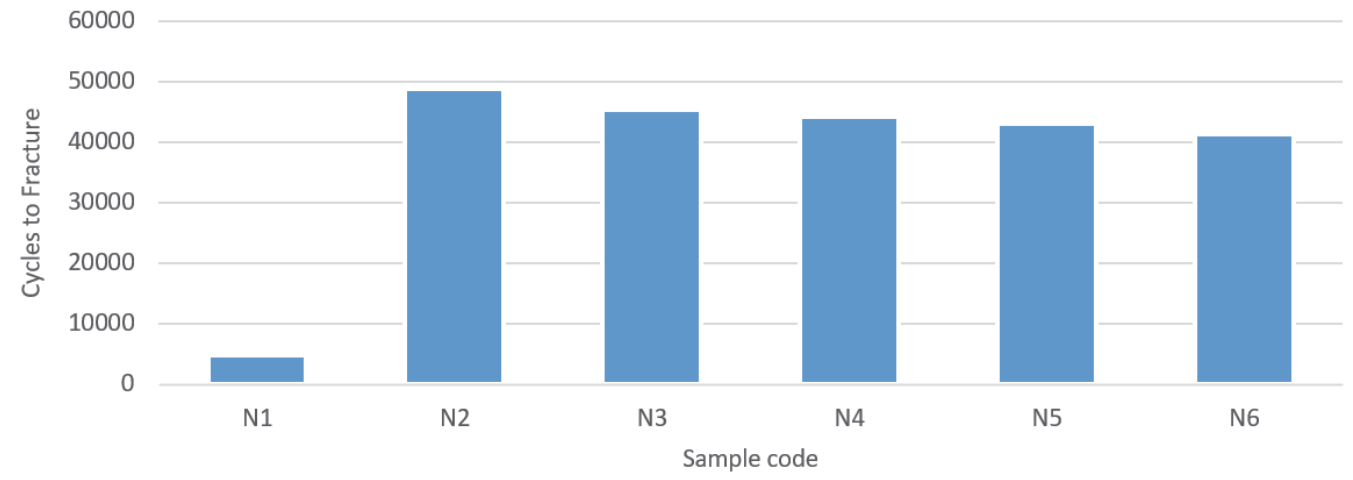

Figure 7: IDT fatigue test results of the modified and the control mixtures.

\section{CONCLUSION}

W

ithin the context of this research study it can be concluded that both SBR and rPET polymers improve physical and mechanical properties of the base binder. The results of moisture susceptibility and dynamic creep tests show that by increasing the ratio of rPET rresistance of the asphalt mixture increases. Also, by increasing the ratio of SBR in fatigue test, resistance of mixture increases. Considering the results of all the tests conducted in this research study it can be said that the modified asphalt with both polymers compared to the base bitumen has better performance. It can also be mentioned that using rPET and SBR is suitable in road asphalt pavement in regions located in deserts where there is a large difference between the day and night temperature as they decrease the rutting in high temperature and reduce the cracking in low temperature.

\section{REFERENCES}

[1] Yang, H., (2004). Pavement Analysis and Design, 1.

[2] Nikolaides, A., (2014). Highway engineering: Pavements, materials and control of quality. CRC Press.

[3] Tafti, M. H., Aqda, S. A. H., Motamedi, H. (2019). The impacts of type and proportion of five different asphalt modifiers on the low-temperature fracture toughness and fracture energy of modified HMA, Frattura ed Integrità Strutturale, 47, pp. 169-185.

[4] Zhu, J., Birgisson, B., Kringos, N. (2014). Polymer modification of bitumen: Advances and challenges, European Polymer Journal, 54, pp.18-38.

[5] Behnood, A., Gharehveran, M. M. (2019). Morphology, rheology, and physical properties of polymer-modified asphalt binders, European Polymer Journal, 112, pp. 766-791.

[6] Gogoi, R. (2015). Performance prediction analyses of styrene-butadiene rubber and crumb rubber materials in asphalt road applications, Materials and Structures, 49, pp. 3479-3493.

[7] Senise, S. (2017). Thermomechanical and microstructural evaluation of hybrid rubberised bitumen containing a thermoplastic polymer, Construction and Building Materials, 157, pp. 873-884.

[8] Lu, X. (2001). Modification of Road Bitumens with Thermoplastic, Polymer Testing, 20, pp. 77-86.

[9] Al-Hadidy, A.I. (2018). Effect of laboratory aging on moisture susceptibility and resilient modulus of asphalt concrete mixes containing PE and PP polymers, Karbala International Journal of Modern Science, 4, pp. 377-381. 
[10] Luo, W.-q., Chen, J.-c. (2011). Preparation and properties of bitumen modified by EVA graft copolymer, Construction and Building Materials, 25, pp. 1830-1835.

[11] Moreno Navarro, F. and Rubio Gamez, M. C., (2012). Influence of Crumb Rubber on the Indirect Tensile Strength and Stiffness Modulus of Hot Bituminous Mixes, Journal of Materials in Civil Engineering, 24, pp. 715-724.

[12] McNally, T. (2011). Polymer modified bitumen: Properties and Characterisation. Woodhead Publishing, 1 th Edition.

[13] Liang, P., Liang, M.(2017). Improving thermo-rheological behavior and compatibility of SBR modified asphalt by addition of polyphosphoric acid (PPA), Construction and Building Materials, 139, pp. 183-192.

[14] Murphy, M. (2000). Bitumens modified with recycled polymers, Materials and Structures, 33, pp. 438-444.

[15] Hussein, A.A., Pei Feng, C. (2017), Effects of high-density polyethylene and crumb rubber powder as modifiers on properties of hot mix asphalt. Construction and Building Materials, 142, pp. 101-108.

[16] Ge, D., Yan, K., You, Z. and Xu, H., (2016). Modification mechanism of asphalt binder with waste tire rubber and recycled polyethylene. Construction and Building Materials, 126, pp. 66-76.

[17] Karahrodi, M.H., Jazani, O.M. (2017). Modification of thermal and rheological characteristics of bitumen by waste PET/GTR blends, Construction and Building Materials, 134, pp. 157-166.

[18] Modarres, A., Hamedi, H. (2014). Effect of waste plastic bottles on the stiffness and fatigue properties of modified asphalt mixes, Materials and Design, 61, pp. 8-15.

[19] El-Naga, I. A., Raga, M. (2019). Benefits of utilization the recycle polyethylene terephthalate waste, Construction and Building Materials, 219, pp. 81-90.

[20] Oglesby, C. H. and Hicks, R. G. (1982). Highway Materials, Chapters 15, 16 and 17, 4th Edition.

[21] Haghnazar, H. and Saneie, M. (2019). Impacts of pit distance and location on river sand mining management. Modeling Earth Systems and Environment, 5(4), 1463-1472.

[22] Yoder, E. J. and Witczak, M. W. (1975). Principles of Pavement Design, Chapter 9, 2nd Edition.

[23] ASTM-D1599, (2001). American Society for Testing and Materials for Determine the optimal bitumen percentage of Asphalt samples.

[24] Tabatabaei, S. A., Kiasat, A., Alkouhi, F. K. (2013). The Effect of Styrene-Butadiene-Rubber (SBR) Polymer Modifier on Properties of Bitumen, International Journal of Materials and Metallurgical Engineering, 7(10).

[25] Ahmad, A. F., Razali, A. R. (2017). Utilization of polyethylene terephthalate (PET) in bituminous mixture for improved performance of roads, Materials Science and Engineering, 203(1). DOI:10.1088/1757-899X/203/1/012005.

[26] Ameri, M., Mohammadi, R. (2017). Evaluation the effects of nanoclay on permanent deformation behavior of stone mastic asphalt mixture, Construction and Building Materials, 156, pp.107-113.

[27] Abson, G. and Burton, C. (1964). Physical Tests and Rang of Propertics, in A. J. Holborg (Ed), Bituminous Materials: Asphalt, 1.

[28] ASTM-D5, (2001). American Society for Testing and Materials for Determining the Penetration grade of Bitumen.

[29] ASTM-D36, (2001). American Society for Testing and Materials for Determining the Softening point of Bitumen.

[30] Chunshui Huang, (2018). A new viscoelastic mechanics model for the creep behaviourof fiber reinforced asphalt concrete, Frattura ed Integrità Strutturale, 45, pp. 108-120.

[31] ASTM-D4402, (2001). American Society for Testing and Materials for Determining the Viscosity of Bitumen.

[32] ASTM-D6924, (2001). American Society for Testing and Materials for Constructing Asphalt Samples.

[33] Yang. H .Huang, (2004). Pavement Analysis and Design, chapter 2.

[34] Ameri, M., Nemati, M., Shaker, H., Jafari, F. (2019). Experimental and numerical investigation of the properties of the Hot Mix Asphalt Concrete with basalt and glass fiber, Frattura ed Integrità Strutturale, 50, pp. 149-162.

[35] ASTM-D4123, (2001). American Society for Testing and Materials for Determining the Resilient modulus of Asphalt mixture.

[36] Goh, S.W., You, Z., (2009). A simple stepwise method to determine and evaluate the initiation of tertiary flow for asphalt mixtures under dynamic creep test, Construction and Building Materials, pp. 3398-3405.

[37] EN13697-25a, (2007). European Standard Test methods for Determine the Dynamic Creep of Asphalt mixture.

[38] AASHTO-T283, (2002). American Association of State Highway and Transportation Officials methods for Determine the Moisture Sensitivity of Asphalt mixture.

[39] Farazmand, P., Hayati, P. (2021). Relationship between microscopic analysis and quantitative and qualitative indicators of moisture susceptibility evaluation of warm mix asphalt mixtures containing modifiers, Frattura ed Integrità Strutturale, 51, pp. 215-224.

[40] Babagoli, R., Mohammadi, R. and Ameri, M. (2017). The rheological behavior of bitumen and moisture susceptibility modified with SBS and nanoclay, Petroleum Science and Technology, pp. 35 1085-1090. 
[41] Boyes, A.J. (2011). Reducing moisture damage in asphalt mixes using recycled waste additives, Master of Science thesis, California Polytechnic State University.

[42] Al-Khateeb, G. G., Ghuzlan, K. A. (2014). The combined effect of loading frequency, temperature, and stress level on the fatigue life of asphalt paving mixtures using the IDT test configuration, International Journal of Fatigue, 59, pp. 254-261.

[43] EN 12697-24, (2007). European Standard Test methods for Determine the Indirect Tensile Fatigue of Asphalt mixture. 